\title{
The Glorious Promise of the Post-Truth World
}

\author{
by Andrew Odlyzko
}

\section{Editor's Introduction}

"Post-truth"-an adjective designated the 2016 Word of the Year by the Oxford English Dictionaries, and the related term "truthiness," have received much public attention recently, and have inspired heated discussions of "fake news" and "alternative facts."

In this article (spoof/parody/satire/dystopia/..., depending on how you read it), the author argues that the essential role of truthiness in human life is underestimated, and that it "is safer to embrace the inevitable and march into the brave new post-truth world." 


\section{The Glorious Promise of the Post-Truth World}

\section{by Andrew Odlyzko}

The crusade against truthiness is misguided. Instead of fighting the spread of the post-truth world, we should welcome it as the next stage in the evolution of human society, liberating us from the cruel constraints of cold reality. This appears to have been the mostly unspoken goal of the human race from the beginning of its existence. Modern technology finally seems to be putting it within our reach. All we need to do is disregard the naysayers and forge bravely ahead on natural paths!

Post-truth, analogous to Stephen Colbert's concept of "truthiness," is an adjective denoting "circumstances in which objective facts are less influential in shaping public opinion than appeals to emotion and personal belief." It has been designated as the Word of the Year 2016 by the Oxford Dictionaries. This honor resulted from this word's sudden rise in prominence, prominence fed by the misplaced fears that it could damage our society.

The advocates of the war on the post-truth world do offer many beguiling arguments. The Internet was acclaimed as leading to a new age of enlightenment through easy communication and universal access to information. Instead, observers see the emergence of an increasingly polluted information environment $[4,9]$. We face torrents of false or at least distorted tweets, video clips, and blog posts. We also observe the formation of many echo chambers, groups that reinforce those groups' chosen visions, selecting what to accept as true, and amplifying each other's biases. There are widespread fears such trends will hurt our society, especially since there is growing evidence of large organized projects to pollute social network discourse and redirect it [7].

This has led to calls for countermeasures. Facebook has promised to respond [14], and Google has already built an extension to the Chrome browser for detecting fake news. There are other burgeoning efforts to provide reliability measures for the information spreading on the Internet and through social networks $[5,10]$.

The argument against such efforts is very simple: They would damage our society and stifle technological progress. Post-truthism is a very natural, inevitable, and in many ways desirable 
stage in the evolution of human society. Even the current craze for fighting truthiness is an example of the post-truth world in action. Contrary to popular opinion, truthiness is not a novel phenomenon, it is just that recently it has intensified, and has caught increased public attention.

Over the ages, we have been freeing ourselves from physical constraints. There are more of us than ever before, we live far longer, and clothing, shelter, and food needs are becoming ever less pressing, to the point that there are more people who are obese than those suffering hunger. Human physical labor has also been declining, replaced first by animals, then by simple machines, and today increasingly by sophisticated robots.

More recently, we have started freeing ourselves from further constraints. Information technologies have been freeing us from routine mental work, and Al promises much more progress in this area.

The natural next step, after freeing ourselves from all this physical and mental drudgery, is to free ourselves from dependence on cruel, inflexible reality. We may never reach a completely post-fact world, but we can come far closer than ever before. Historically, Homo sapiens has shown a greater appetite for humbug than for facts, as Charles Mackay, P.T. Barnum, and others demonstrated long ago $[1,8]$. But cold facts often intervened, whether in the shape of a saber-tooth tiger or the growling of an empty stomach. Now we can push reality much further away and live in our dream worlds.

Lest you recoil at this notion, recall just how important humbug has been to human progress. Silicon Valley is famous, among other things, for its "fake it till you make it" mantra. But this is just the most refined form of an ancient practice that has been key to the success of innumerable scientists and engineers for centuries. Promoters of new technologies usually offer promises of costs, of time to deliver, and of performance.

Just how often has even one of those three promises been met? For some of the dismal statistics on this score, in well-established technologies to boot, see [3]. In order to advance technologically, we apparently need the public and decision makers to repeatedly fall for the promises of honey-tongued promoters, to enter analogues of the Steve Jobs "reality distortion field." An effective fake news detecting method could easily destroy the illusions that progress is based on.

Homo sapiens is not just a deeply irrational species, it is a herd species. Although groupthink is universally deprecated, it is an essential element to the functioning of most organizations. The best teams appear to require their own "reality distortion fields" to be effective. Sports teams have to be psyched up for best play, to be convinced they can win no matter what the odds. 
Similarly, teams of programmers apparently have to be led to truly believe that modifying code to make the employer's web page load a tenth of a second faster will revolutionize the world. Could such processes survive exposure to effective reality checks?

It is not only sports teams and high-tech startups that depend on groupthink that is at variance with reality. Scholarly research is at its essence a series of echo chambers, with specialties establishing their own societies, journals, and conferences. Incoming students are socialized and absorb the reigning dogmas, which prepares them to fiercely resist any novel ideas that threaten the consensus, and to ignore or distort inconvenient facts. Often this degenerates into pseudo-sciences or glass bead games, as the frequently tenuous connections to reality are diluted.

Even at its best, the modern academic research process produces very unreliable results. Historians of science and technology have known this for ages. Today it is being systematically explored through careful studies of the peer-reviewed literature, cf. [11]. But that is simply how progress occurs, apparently the inevitable adjunct to the herd nature of our species. As Max Planck famously opined, and as the example of Einstein's refusal to accept the reality of quantum mechanics confirms, "a new scientific truth does not triumph by convincing its opponents and making them see the light, but rather because its opponents eventually die, and a new generation grows up that is familiar with it." That new generation then goes on to establish its own orthodoxy, by building up its own echo chamber. Do we dare throw a monkey wrench into this process?

It seems far better to follow the natural and inevitable path. Politicians and marketers have been pioneers in moving into the post-truth world and will certainly not be stopped from exploiting it. Let's not allow them to monopolize it! Let's develop better methods for individuals and groups to create their own illusory worlds, deciding on their visions of reality. Video game, virtual reality, and the even more recent augmented reality technologies should be among the building blocks. The methods currently being developed and deployed to fight truthiness should also yield variants that promote it. Tools to construct the webs of trust that are promised to provide reality checks can be designed from the start to enable construction of alluring virtual worlds far removed from reality.

Let's not be deterred by inveterate pessimists. There might be some dangers, but society has managed to deal with negative side effects of many technologies that were attractive enough. For example, the number of cars is still growing explosively worldwide, even though they are involved in over a million human fatalities per year. We will surely manage to deal with the problems posed by truthiness. Any irremediable disadvantages of the post-truth world should be a small price for unleashing all the creativity that has lain dormant! 
Of course, such a world will involve competing realities. It will also be based on obfuscation and attempts to fool others. But cheating others and detecting cheating is just what people are best at. Evolutionary psychologists argue that this was key to the development of human intelligence, and support this by data showing that the more intelligent a species is, the more social cheating it engages in [12].

The future of this train of thought points to has many attractive features. In particular, it suggests that fears of technological unemployment are exaggerated. Yes, more and more of our current jobs will be automated. However, it has long been obvious that there will be plenty of jobs in providing geriatric care. The post-truth world promises plenty of additional jobs confusing others (assisted by information systems tools, of course, which will increase the demand for technologists and social scientists) and penetrating the misdirections and obfuscations of others.

It is not only society at large that will benefit from such developments. So will individuals. We will finally have a solution to the privacy problem. Technology is enabling the collection of increasingly detailed and intimate information about us, and many organizations, commercial and governmental, are determined to collect it. So, in spite of much hand-wringing and many well-intentioned efforts, the disappearance of privacy appears inevitable.

But in a post-truth world the erosion of privacy will not be a serious issue! We'll just select which of the myriad "facts" about us in the databases are to matter. It is a very natural development. It has some precursors, such as the Japanese notions of honne and tatemae, which distinguish between a person's inner feelings and desires and the public face. Think of each person being represented by multiple avatars, with the most appropriate one chosen for each occasion.

If we insist on establishing solid grounding in facts, we will run incalculable risks to individuals. To paraphrase Dostoevsky's Grand Inquisitor, Homo sapiens is not ready for the unvarnished truth. Human life depends not only on fooling others, but also on fooling ourselves, and the ability to do so could be impaired by many of the methods being developed to fight truthiness. There would be some benefits, of course. Had that iconic tech hero, Steve Jobs, been more grounded in reality, he surely would not have spent a year trying "alternative medicine," and might be alive today. But had he been more grounded in reality, would he have achieved anywhere near as much as he had?

In general, the human race owes much to the various irrational traits that animate people, cf. $[6,13]$. One of the most important is the overconfidence bias. How many of the most 
spectacularly successful entrepreneurs, scientists, or technologists would have embarked on their projects had they known the real odds facing them?

Let us close by citing another of the innumerable human biases whose function could be destroyed by insisting on close connections to reality. That is the Lake Wobegon Effect, in which "all the children are above average." Various instances of it are well-documented, including a study of the faculty at a research university in which around $70 \%$ put themselves in the top $25 \%$ in teaching ability [2]. But there are some groups that appear to be exceptions to this phenomenon. The somewhat controversial depressive realism hypothesis holds that depressed individuals make more accurate appraisals of the world and their own standing than the population at large. Of course, the studies supporting this hypothesis show correlation, not causation. So we do not know for certain that forcing people to face objective truth will push them into depression. But do we dare try the experiment?

It is surely far safer to embrace the inevitable and march into the brave new post-truth world.

In deference to the holdouts who continue to place excessive weight on objective reality and obsolete standards of scholarly discourse, I do hereby acknowledge the contributions of numerous friends and colleagues. Their frequently troglodytic comments significantly contributed to this piece. They are not named to enable them to disclaim any connection with it. Or, in extremis, even any knowledge of it.

\section{References}

1. Barnum, P.T. The Humbugs of the World: An Account of Humbugs, Delusions, Impositions, Quackeries, Deceits and Deceivers Generally, in All Ages. Carleton, 1866.

2. Cross, K.P. Not can, but will college teaching be improved? New Directions for Higher Education 1977 (1977), 1-15.

3. Flyvbjerg, B., Bruzelius, N. and Rothengatter, W. Megaprojects and Risk: An Anatomy of Ambition. Cambridge University Press, 2003.

4. Hayes-Roth, R. Truthiness Fever: How Lies and Propaganda Are Poisoning Us and a Ten-Step Program for Recovery. Booklocker.com, 2011.

5. Indiana University. Hoaxy project, http://hoaxy.iuni.iu.edu/.

6. Kahneman, D. Thinking, Fast and Slow. Farrar, Straus and Giroux, 2011. 
7. King, G., Pan, J., and Roberts, M.E. How the Chinese government fabricates social media posts for strategic distraction, not engaged argument. American Political Science Review, 2017; http://gking.harvard.edu/50c.

8. Mackay, C. Extraordinary Popular Delusions and the Madness of Crowds. R. Bentley, 1841.

9. Manjoo, F. True Enough: Learning to Live in a Post-Fact Society. Wiley, 2008.

10. Media Bias/Fact Check; https://mediabiasfactcheck.com/.

11. Open Science Collaboration. Estimating the reproducibility of psychological science. Science 349, 6251 (Aug. 28, 2015); http://science.sciencemag.org/content/349/6251/aac4716.

12. Trivers, R. The Folly of Fools: The Logic of Deceit and Self-Deception in Human Life. Basic Books, 2011.

13. Twain, M. On the decay of the art of lying. In The Stolen White Elephant, Etc. Osgood, 1882.

14. Zuckerberg, M. post about misinformation, Nov. 18, 2016; https://www.facebook.com/zuck/posts/10103269806149061

\begin{abstract}
About the Author
Andrew Odlyzko (odlyzko@umn.edu) is a mathematician and a former head of the University of Minnesota's Digital Technology Center and of the Minnesota Supercomputing Institute and before that was a researcher and research manager at Bell Labs and AT\&T Labs.
\end{abstract}

DOI: $10.1145 / 3061712$

Copyright held by owner. 